
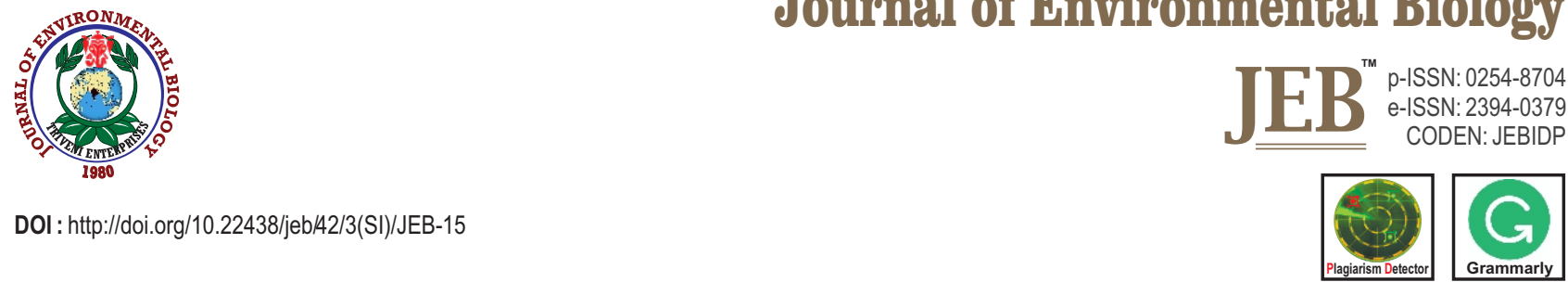

\title{
The effects of temperature and pH change on the snapping sound characteristic of Alpheus edwardsii
}

\author{
K.S. Lai ${ }^{1,2}$, Z.Z. Goh ${ }^{2}$ and S.M. Ghazali ${ }^{2 *}$ \\ ${ }^{1}$ Freshwater and Invasion Biology Laboratory, Department of Biological Sciences, Faculty of Science, National University of Singapore, 14 Science \\ Drive 4, 117558, Singapore \\ ${ }^{2}$ Department of Earth Science and Environment, Faculty of Science and Technology, University Kebangsaan Malaysia, Bangi, 43600, Malaysia \\ *Corresponding Author Email : shahriman@ukm.edu.my
}

\section{Abstract}

Aim: The current study undertook manipulative experiments to observe changes in snapping shrimp sound signals in relation to temperature and pH changes.

Methodology: Sounds of intertidal snapping shrimp (Alpheus edwardsii) sequentially exposed to different temperature/pH treatments manipulation for a period of 2 week each, were recorded in the laboratory and analysed. The acoustic characteristics of snapping sound signal were examined to relate to the change in temperature, $\mathrm{pH}$ and combination of both parameters

Results: Our results showed that there was a significant reduction in the frequency of peak amplitude of snapping sound wave following a two week exposure to a combination of temperature and $\mathrm{pH}$ treatments. The frequency of snapping shrimp sound decreased by approximately $30 \%$ when exposed to a $2^{\circ} \mathrm{C}$ increase in temperature and a 0.7 unit decrease in $\mathrm{pH}$, however, elevated temperature alone caused no significant effect on the peak frequency of snapping shrimp sound.

Interpretation: The finding suggests that following the prediction values of temperature and $\mathrm{pH}$ changes due to climate change in the coming century may implicate the ambient noise at habitats where snapping shrimps dominate.

Key words: Bioacoustics, Climate change, Snapping shrimp

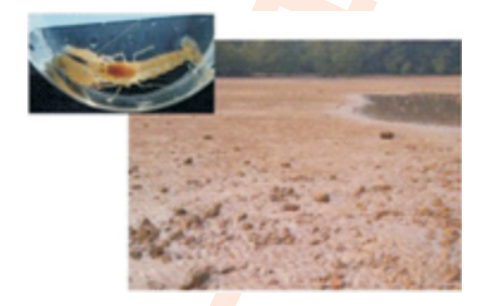

Alpheus edwardsii collected from the field

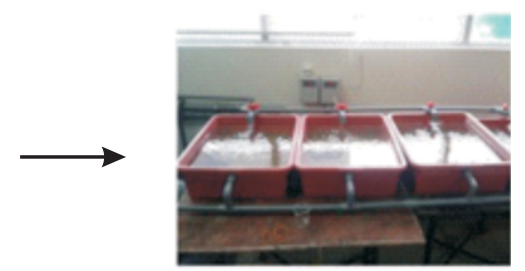

Live samples kept in holding tanks

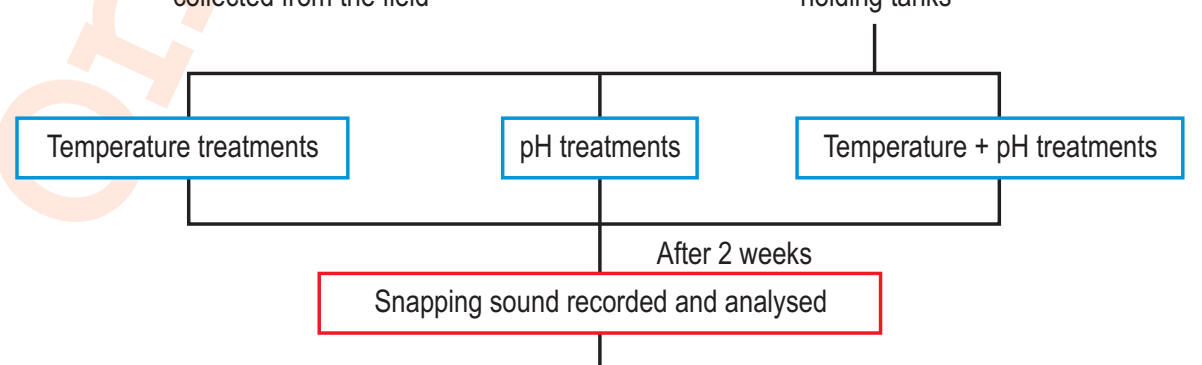
reduction in the peak frequency of snapping sound, however, elevated temperature showed in significant effect to sound signal of Alpheus edwardsii

How to cite : Lai, K.S., Z.Z. Goh and S. M. Ghazali: The effects of temperature and pH change on the snapping sound characteristic of Alpheus edwardsii. J. Environ. Biol., 42, 832-839 (2021). 


\section{Introduction}

The ambient noise of coastal marine habitat is dominated by the sounds of snapping shrimps. The loud sound $(\sim 210 \mathrm{~dB}$ re $1 \mu \mathrm{Pa})$ is produced from the snapping action of its enlarged chelae that causes the formation and implosion of cavitation bubbles . Underwater snapping sounds characterized by their wide frequency range $(2-100 \mathrm{kHz}$ ) and high amplitude can be detected using a hydrophone throughout the day in marine habitats where snapping shrimps dominate. Past studies show that snapping shrimp sounds in underwater reef noise could mediate larval settlement and swimming behaviour of many marine species . This indicates that the sound of snapping shrimps in nature plays an important role as navigational cue for marine organisms to find suitable habitat and food, hence, attraction for a wide range of marine species

For many marine animals, temperature is one of the important factors that influence their distribution and abundance at certain habitats. Past studies have shown that poikilotherms, such as fish and aquatic invertebrates require a critical temperature to grow and reproduce where elevated temperature usually causes a range of negative effects. Changes in temperature may lead to hypoxia caused by anaerobic metabolism of body cells, especially in extreme temperatures. In addition, growth rate (Mann, 1979) and hormonal activities of marine invertebrates have been found to be vulnerable at elevated temperature. Moreover, extreme temperatures are lethal to marine animals and in many cases can decimate whole population, such as coral colonies. Several studies in recent years have examined the effects of environmental drivers on sound production by snapping shrimps in different regions have found that snap rate of snapping shrimps are positively correlated to elevated temperature (Bohnenstiehlet al., 2016; Kim et al., 2011; Lillis and Mooney, 2018). While these studies have focused on the relationship of environmental variables to snapping behaviour of snapping shrimp, however, studies on the effect of elevated temperature on the qualitative characteristics of snapping shrimp signals are meagre.

Other than temperature, $\mathrm{pH}$ of seawater has been found to be crucial to many marine taxa, especially to calcifying organisms. Acidification of seawater that affects the concentration of carbonate ions has been found impactful to exoskeleton and shell calcification rate . Varying effects of ocean acidification on Crustaceans have been broadly discussed in past studies, although its specific effect on bioacoustical aspects is rather vague. The mortality rate of northern shrimp, Pandalus borealis increased up to $90 \%$ after 30 week exposure to elevated carbon dioxide concentration (Branch et al., 2013). With regards to snapping shrimp, it was reported that its soniferous behaviour is altered in ocean acidification conditions. Suppression of sonic activity measured in terms of both overall sound levels and snapping frequency of snapping shrimp noise has been reported
(Rossi et al., 2016). Future changes in average seawater temperature and acidity are likely to impact snapping shrimp dominated coastal marine soundscapes. Consequently, such a big scale change in the soundscape can be deciphered from a better understanding at finer scale, qualitative changes of individual snapping sound as suggested in this study.

The changes in average temperature and $\mathrm{pH}$ of seawater have been linked to global climate change phenomenon. According to 2013 IPCC Fifth Assessment report, seawater temperature is predicted to increase by $2^{\circ} \mathrm{C}$ within the next century (Kirtman et al., 2013). In view of the above, this study aimed to identify the impact of $\mathrm{pH}$ and temperature in accordance to this global warming prediction scenario on the bioacoustics of snapping shrimp.

\section{Materials and Methods}

Snapping shrimps (Alpheused wardsii) were collected from an intertidal mudflat near Penyabong beach in Johor, Malaysia. The sampling area predominantly comprises muddy sand with scattered rocks and oyster shells. Snapping shrimps were collected under small rocks in tide pools by using scoop net or bare hands during low tide. Samples were then transported live to the marine bioacoustic laboratory at the Universiti Kebangsaan Malaysia in Bangi for subsequent experiments. In laboratory, the body length of each shrimp was measured and kept in six different holding tanks $(50 \mathrm{~cm} \times 25 \mathrm{~cm} \times 15 \mathrm{~cm}$ ) according to their body size $(21-25 \mathrm{~mm})$ with continuous supply of recirculating filtered seawater. Water temperature and salinity were maintained at $28^{\circ} \mathrm{C}$ and 33 psu respectively. The shrimps were fed with sinking pellets twice a day and their conditions were monitored on daily basis. Each shrimp was used only once throughout the experiment and were euthanized in $70 \%$ ethanol solution at the end of the experiment.

To examine the effect of temperature and $\mathrm{pH}$ on the snapping sound of snapping shrimp, two rectangular glass aquariums were set-up in a controlled environment. Each aquarium was $30 \mathrm{~cm}$ high, $60 \mathrm{~cm}$ long and $30 \mathrm{~cm}$ wide. The aquariums were filled up to $20 \mathrm{~cm}$ deep with filtered artificial seawater. In total, the experiment consisted of three treatments Effects of temperature, Effect of $\mathrm{pH}$ and Combined effects of $\mathrm{pH}$ and temperature. The temperature and $\mathrm{pH}$ treatment were partly based on the IPCC predictions of global warming scenario in 2100 and 2300 respectively. To investigate the effect of forecasted temperature and $\mathrm{pH}$ changes on the acoustic outputs (peak frequency) generated by snapping shrimp, three temperature and $\mathrm{pH}$ were used in this study, including combination of these two variables. The temperature was increased by $1^{\circ} \mathrm{C}$ for every temperature treatment, from $28^{\circ} \mathrm{C}$ (control) to $30^{\circ} \mathrm{C}$. Meanwhile for $\mathrm{pH}$ treatments, $\mathrm{pH}$ was set at 8.1 (control), 7.7 and 7.4. Treatments for simultaneous effect of temperature and $\mathrm{pH}$ were the combination of readings mentioned 


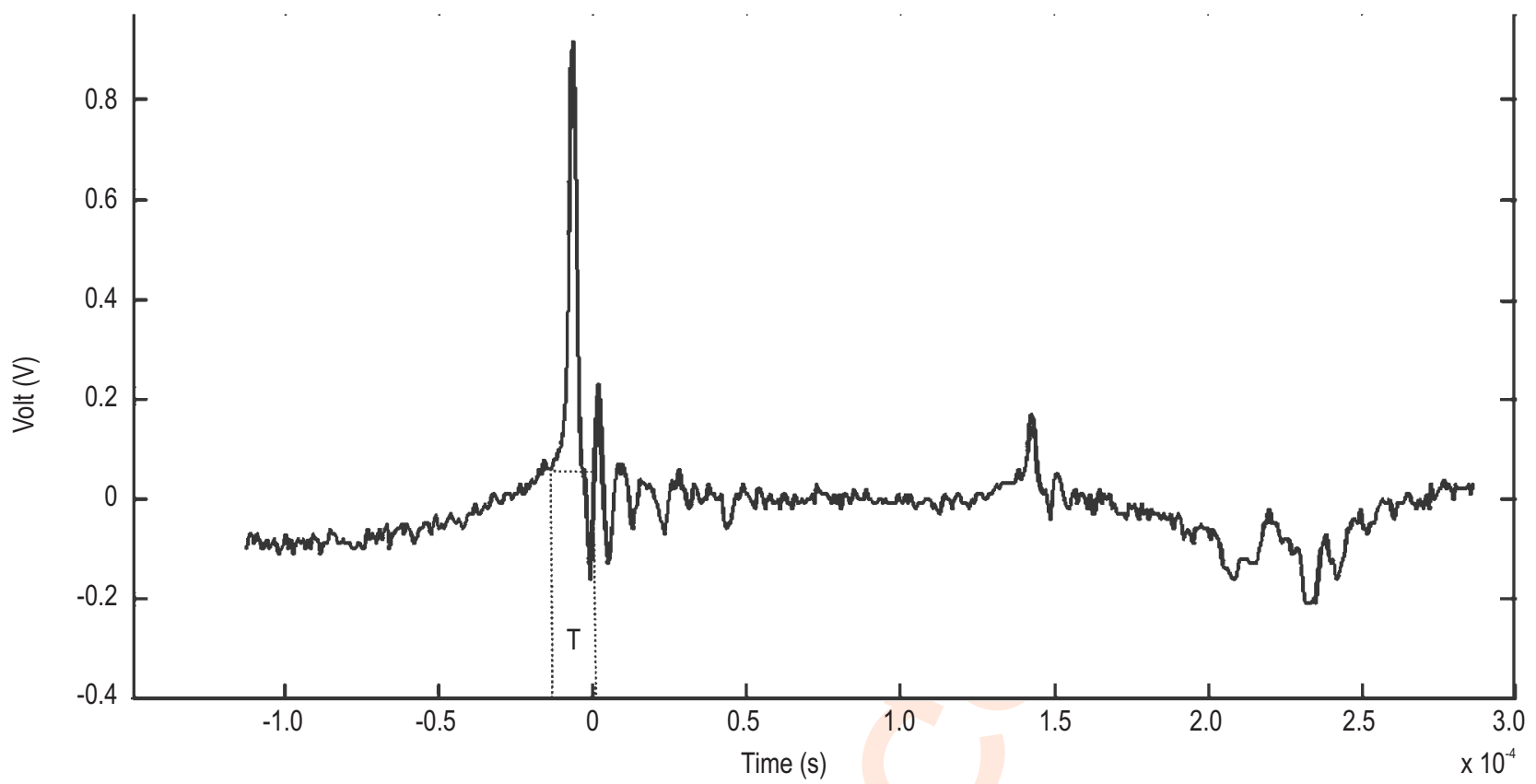

Fig. 1 : Example waveform of a snapping shrimp snap where $T=0.00028 \pm 0.000075 \mathrm{~s}$, is the period of first peak used to calculate peak frequency $(1 / T)$ of the snapping sound.

above. The temperature of seawater was manipulated by using an aquarium heating system $(30 \mathrm{~W})$ and consistently monitored the temperature using a glass thermometer. Meanwhile, $\mathrm{pH}$ of seawater was controlled and maintained by the continuous supply of carbon dioxide gas into the seawater. Carbon dioxide was bubbled into the seawater through an air stone at fixed rate and the $\mathrm{pH}$ level of seawater was regularly monitored using a calibrated pH meter (Extech, model PH100, USA) throughout the duration of the experiment. The assumption of this experiment was that the level of temperature and $\mathrm{pH}$ exposures were not lethal, and the resulting snapping sound was due to the adaptation of snapping shrimp to various exposures.

Individual snapping shrimp $(\mathrm{n}=3)$ was held separately in three small plastic rectangular cages $(10 \mathrm{~cm} \times 10 \mathrm{~cm} \times 10 \mathrm{~cm}$ ) inside a single glass aquarium. They were kept under controlled temperature $\left(28^{\circ} \mathrm{C}\right)$ and $\mathrm{pH}(8.1)$ for a period of five days for the shrimps to acclimatise to laboratory conditions. The 'before treatment' snapping signals $(n=10)$ of each snapping shrimp were recorded after five days. Following that, the same snapping shrimp was transferred to experimental tank maintained at various temperature $\left(28^{\circ} \mathrm{C}, 29^{\circ} \mathrm{C}\right.$ and $\left.30^{\circ} \mathrm{C}\right)$ and $\mathrm{pH}(8.1,7.7$, 7.4) for treatments. The shrimp were then exposed to these experimental conditions for a period of two weeks each. The 'after treatment' snapping sounds of snapping shrimps were recorded again $(n=10)$ at the end of two week exposure.

Snapping shrimp sounds were recorded in a rectangular polycarbonate tank $(150 \mathrm{~cm} \times 150 \mathrm{~cm} \times 100 \mathrm{~cm})$. The tank was filled with artificial seawater upto $80 \mathrm{~cm}$. Underwater snapping sounds were recorded using a hydrophone (Burns Electronics Aquaear model CR30-40 and HP-A1 amplifier, Australia) connected to a digital sound recorder (Edirol R09HR, Japan) and saved in a Secured Digital (SD) card as uncompressed format (.wav). Bit depth and sampling rate were set at 16 bits and 44.1 $\mathrm{kHz}$ respectively. Individual snapping shrimp was transferred from their plastic cages into a polyethylene bag and placed inside the recording tank. It was assumed that the polyethylene bag was acoustically invisible and did not affect the sound propagation due to relative thickness of bag in comparison to sound wavelength as well as small difference in acoustic impedance between polyethylene and seawater. The shrimp was positioned in the middle of the tank, $75 \mathrm{~cm}$ from the edge of the wall, $40 \mathrm{~cm}$ from the bottom of the tank and laterally $20 \mathrm{~cm}$ from the hydrophone. The shrimp was then stimulated for producing the snapping sound by occasionall approaching the bag with a small painting brush. Ten snapping sounds from each snapping shrimp were recorded during each recording session. The effect of tank resonance was calculated following Akamatsu et al. (2002), where the minimum resonance frequency was $1174 \mathrm{~Hz}$ and the cut-off frequency in lateral direction was $1062 \mathrm{~Hz}$. Assuming that the expected peak frequency of snapping sound signal was higher (above $2000 \mathrm{~Hz}$ ) than the minimum resonance frequency of the tank, it could be assumed that the effect of tank resonance was negligible. The frequency of spectrum was also higher than the cut-off frequency hence, the distance $(20 \mathrm{~cm})$ between the shrimp and hydrophone was acceptable.

Recorded sounds were analysed by software RAVEN Pro 1.4 (Bioacoustics Research Program, Cornell Laboratory of 
Ornithology, Cornell, NY, USA) and statistical analysis was done by R 4.0.0 (R Core Team 2020) with ggplot2 (Wickham, 2016) and doBy (Højsgaard and Halekoh, 2020) packages. The peak frequency of snapping signal sound wave was calculated by the formula $1 / T$, where $T$ is the period of first cycle (signal with peak amplitude) of snapping sound signal waveform. The example of a single snap sound signal and the measurement of $T$ in the waveform is shown in Fig. 1. The sound peak frequencies were analysed using paired t-test to examine the effect of exposure to temperature and $\mathrm{pH}$ treatments.

\section{Results and Discussion}

The temperature experiments showed that the peak frequency of snapping sound increased moderately after 2 week exposure to elevated temperature (Fig. 2). For the control experiment, the mean peak frequency increased from $4612 \mathrm{~Hz}$ to $4792 \mathrm{~Hz}$. This revealed that there was a variation in the sound signals within the same individual of snapping shrimp. However, the paired t-test results proved that the differences were minor and statistically in significant. Similar trend was also observed in control experiment for $\mathrm{pH}$ treatments. At elevated temperature conditions, the mean peak frequency of snapping shrimp increased from $3440 \mathrm{~Hz}\left(29^{\circ} \mathrm{C}\right)$ and $3172 \mathrm{~Hz}\left(30^{\circ} \mathrm{C}\right)$ to $3678 \mathrm{~Hz}$ and $3187 \mathrm{~Hz}$ respectively. However, none of the treatments showed significant changes in respective sound peak frequencies. Consequently, this study showed that elevated temperature alone had minimum effect on the peak frequency of snapping shrimp snapping sounds. Previous studies which examined the snapping shrimp sound patterns in tropical habitats reported that small increase in temperature had no apparent influence on the high-frequency sound levels of snapping shrimp (Everest, 1948; Johnson et al., 1947; Knowlton and Moulton, 1963). Nevertheless, more recent reports revealed that snap rates of snapping shrimps were positively correlated with environmental parameters, including temperature and light, both in field and controlled experiments (Bohnenstiehl et al., 2016; Lillis and Mooney, 2018). Even so, none of the studies examined the effect of elevated temperature on the individual sound signals.

A modest rise in the snapping shrimp signals may be attributed to shorter pulse duration of first pressure peak at elevated temperature. Generally, it is thought that the frequency of sound underwater is independent of temperature although its propagation speed is directly proportional to temperature. One possible explanation is that the size of a single cavitation bubble expands rapidly at higher temperature, which leads to bubble collapse at shorter pulse duration with higher frequency. Kim et al. (2010) reported that the difference between sound spectra and pulse duration of snapping shrimp is related to the size of cavitation bubble and shape of chelae. In relation to this study, it appears that $1-2^{\circ} \mathrm{C}$ temperature increase did not affect the formation of cavitation bubbles.
In addition, the results of this study also suggest that prolonged temperature elevation of $1-2^{\circ} \mathrm{C}$ alone did not affect the mechanics of sound production by the enlarged chelae. Generally, shallow waters of tropical intertidal zones similar to the study site were subjected to large daily temperature range where daily temperature fluctuated by as much as $10^{\circ} \mathrm{C}$ above ambient temperature. Although most intertidal fauna are physiologically adapted to short daily temperature change, the non-lethal effect of longer exposure to temperature elevation that emulate global warming is less known. The physical property of the chelae is believed to play an important role in production of snapping sound due to high-energy mechanism of snaps. Studies focusing the structure and properties of snapping shrimp's chelae as functions of temperature are scarce Verma and Tomar (2014). Investigated the effect of temperature on the structural nanomechanical property of shrimp exoskeleton. The hardness values were found to reduced from around $1.6 \mathrm{GPa}$ at $30^{\circ} \mathrm{C}$ to approximately 1.2 $\mathrm{GPa}$ at $80^{\circ} \mathrm{C}$ for the shrimp, Pandalus platyceros. This suggests that exposure at extreme temperature for a period of time could reduce the hardness of shrimp's exoskeleton unlike the relatively small increase in temperature in this experiment.

The peak frequency of snapping sound for control treatment at pH 8.1 was increased from $3298 \mathrm{~Hz}$ to $3455 \mathrm{~Hz}$. Meanwhile, at pH 7.7, the peak frequency was decreased from $3042 \mathrm{~Hz}$ to $2815 \mathrm{~Hz}$. However, both peak frequency changed for pH 8.1 (control) and 7.7 treatment were not significantly different. However, a significantly difference in sound levels with a decreased of $2625 \pm 558 \mathrm{~Hz}$ to $2504 \pm 760 \mathrm{~Hz}$ after two weeks exposure at pH 7.4 (paired t-test: $t=2.4673, d f=29, p=0.01976$ ) was noted our results indicate that the sound signals of snapping shrimp remain undisturbed at modest decrease in $\mathrm{pH}$ until a specific level of acidification was meet i.e. pH 7.4 as found at in this study (Fig. 2). Seawater acidification has been reported to adversely affect marine animals. The calcification and growth rate of many marine decapods such as tiger prawn , shiba shrimp , and whiteleg shrimp have reported to be varyingly affected by low $\mathrm{pH}$ level or high concentration of dissolved carbon dioxide. This study indicates that the structural property of chelae such as hardness might play an important role in the snapping mechanism of snapping shrimps. Lower calcification and stunted growth rate due to acidification as might affect some of the chelae structural properties of snapping shrimp (Kurihara et al., 2008). Rossi et al. (2016) reported that sound levels and the rate of snapping signals decreased after 3 months of elevated $\mathrm{CO}_{2}$ exposure in controlled laboratory experiment but detected no significant differences. Further investigation is required to see if short period of exposure to a greater decrease in $\mathrm{pH}$ could potentially lead to physicomechanical impairment of chelae due to a reduction in calcification rate.

The combined $\mathrm{pH}$ and temperature treatment experiment showed that the snapping sound peak frequency had decreased 

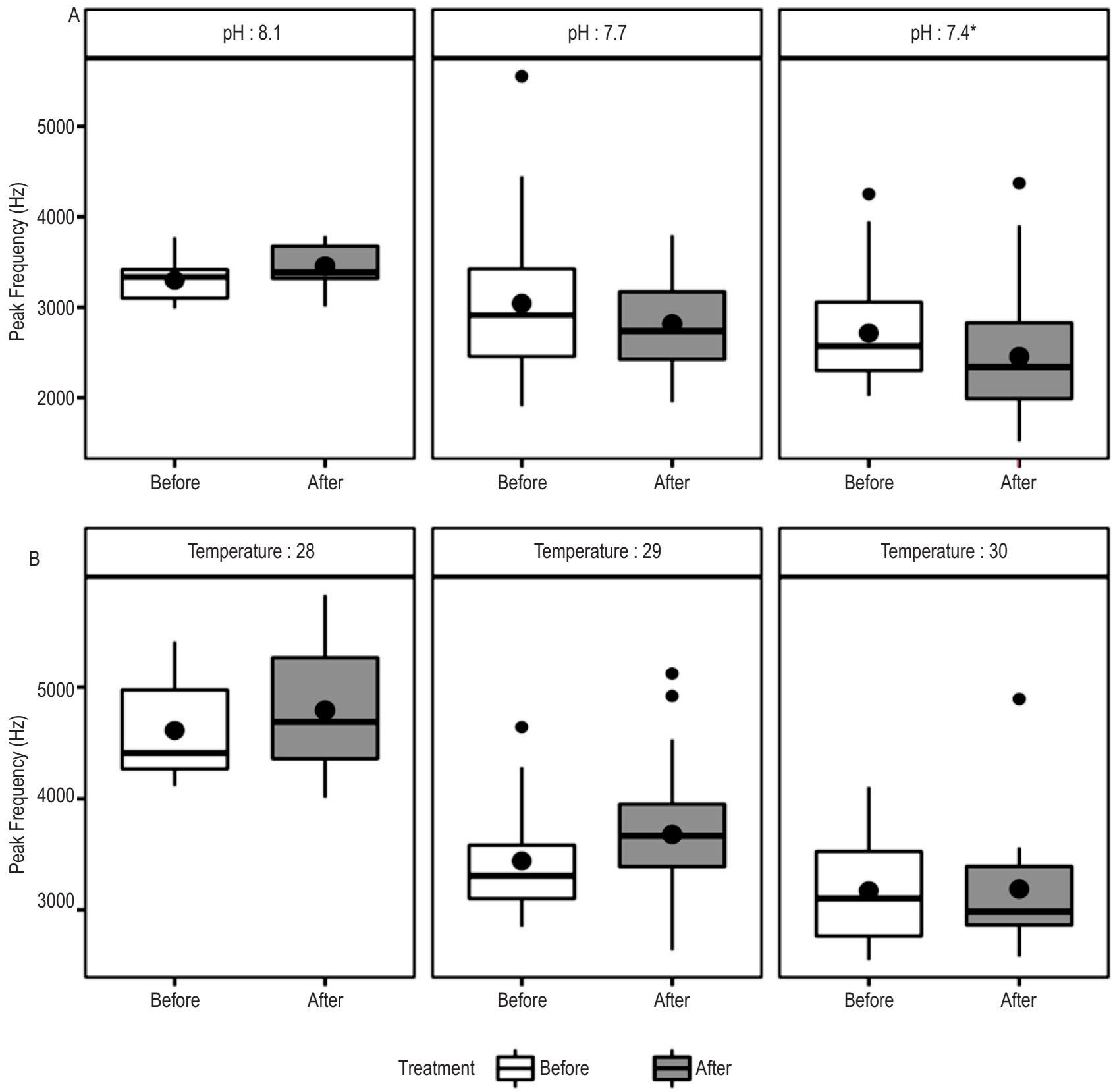

Fig. 2 : Boxplots showing the changes in peak frequency of Alpheus edwardsii after 2 wk exposure to different $\mathrm{pH}$ and temperature conditions. A. pH treatments (temperature fixed at $28^{\circ} \mathrm{C}$ ); B. temperature treatments ( $\mathrm{pH}$ fixed at $\mathrm{pH}$ 8.1). ${ }^{*}$ indicates significant difference $(\mathrm{p}<0.05)$ and mean is plotted with enlarged black point.

significantly from $2850 \mathrm{~Hz}$ to $2584 \mathrm{~Hz}$ after a 2 week exposure to $29^{\circ} \mathrm{C}$ and $\mathrm{pH} 7.7$ (paired t-test: $\mathrm{t}=3.0669$, $\mathrm{df}=29, \mathrm{p}=0.00465$ ) (Fig. $3 \mathrm{~A})$. Fig. $3 \mathrm{~B}$ and $3 \mathrm{C}$ shows a significant reduction of peak frequency in both $29^{\circ} \mathrm{C}$ and $\mathrm{pH} 7.4$ treatment (paired t-test: $\mathrm{t}=3.433, \mathrm{df}=29, \mathrm{p}<0.0021$ ) and $30^{\circ} \mathrm{C}$ and $\mathrm{pH} 7.7$ treatment (paired t-test: $t=4.532, \mathrm{df}=29, \mathrm{p}<0.0001$ ) by approximately 400 $\mathrm{Hz}$ and $700 \mathrm{~Hz}$ respectively. Treatment at $30^{\circ} \mathrm{C}$ and $\mathrm{pH} 7.4$ experienced a significant drop in mean peak frequency from 3966 $\mathrm{Hz}$ to $2703 \mathrm{~Hz}$, which is equivalent to approximately $30 \%$ of sound level reduction (paired t-test: $t=14.987, d f=29, p<0.0001$ ) (Fig. 3D). This result showed that the mean peak frequency of snapping sounds were significantly reduced when low $\mathrm{pH}$ and temperature rise occurred simultaneously.

Our finding indicate a synergetic effect of environmental temperature and $\mathrm{pH}$ on the bioacoustics of intertidal snapping shrimps. As a consequence, such a change in snapping shrimp acoustics may implicate changes in the general characteristics of 
A. 29 Celsius; $7.7 \mathrm{pH}^{*}$

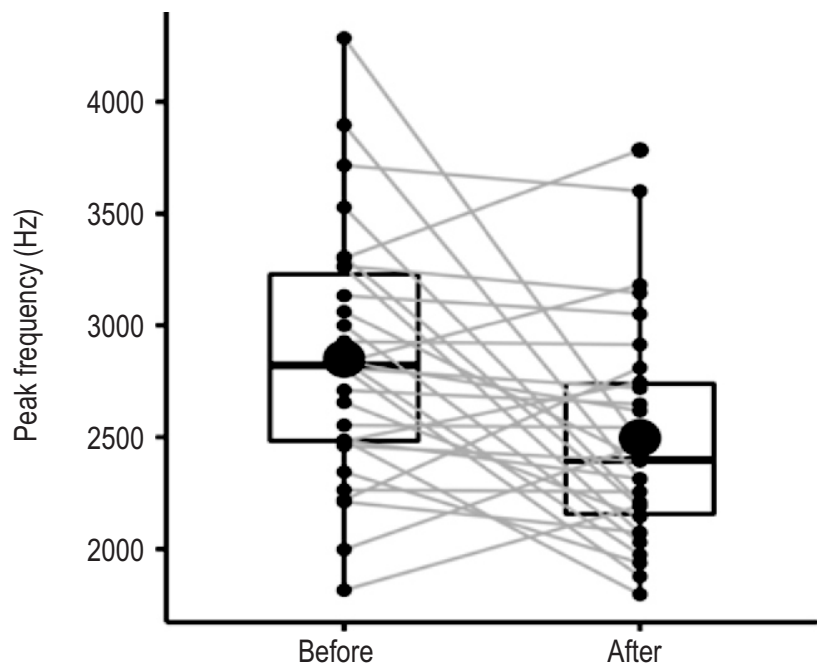

C. 30 Celsius; $7.7 \mathrm{pH}^{* *}$

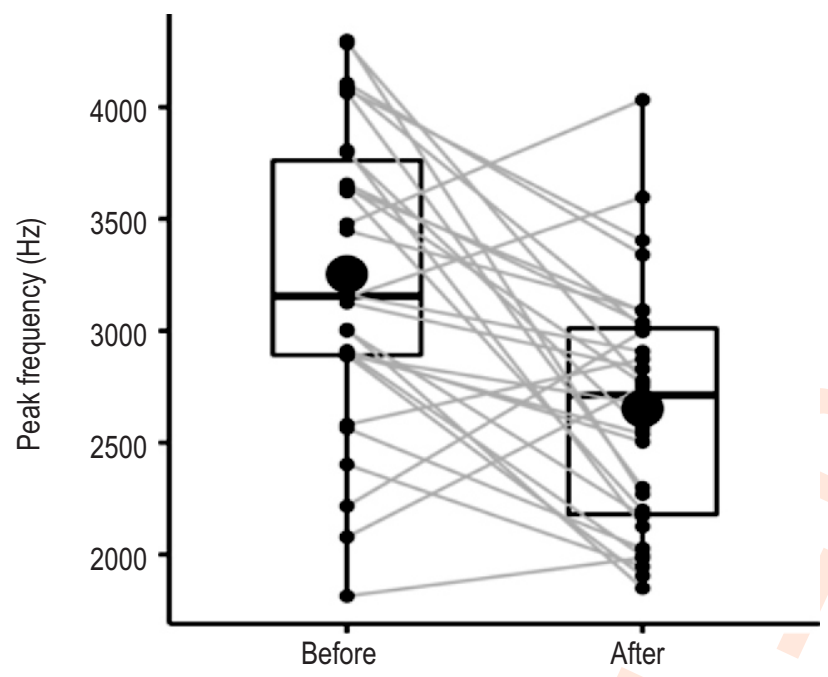

B. 29 Celsius; $7.4 \mathrm{pH}^{*}$

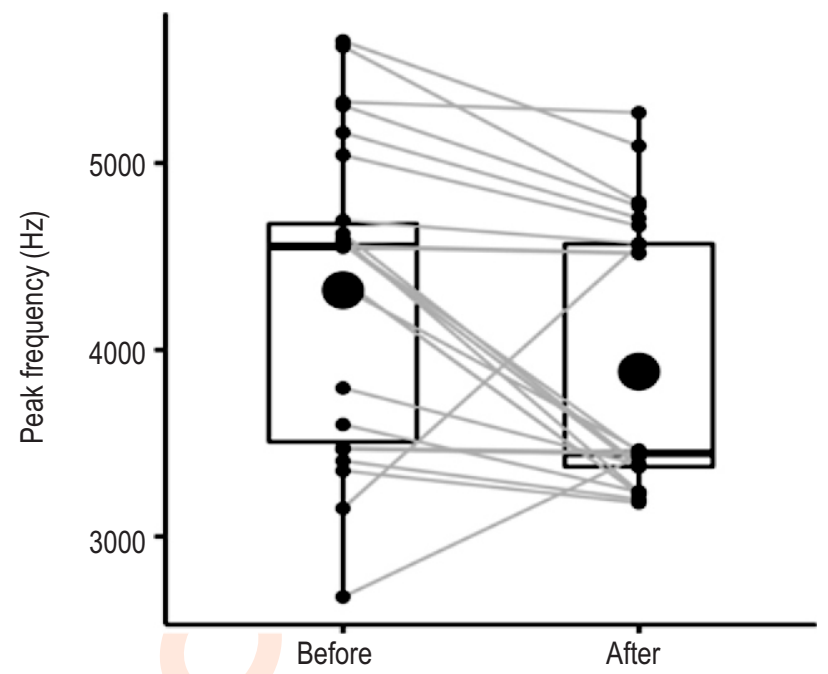

D. 30 Celsius; $7.4 \mathrm{pH}^{* *}$

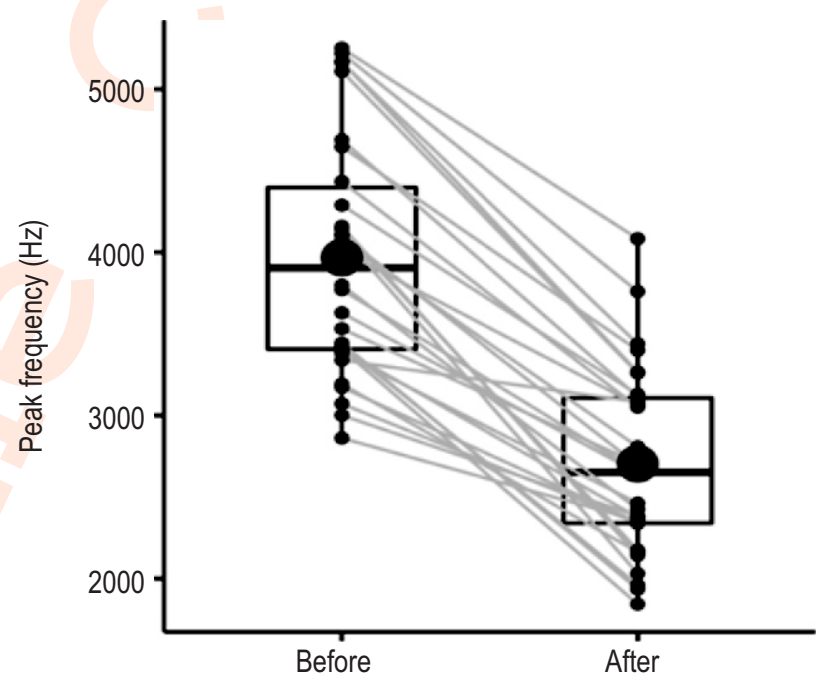

Fig. 3 : Simultaneous effect of temperature and pH on snapping shrimp signals after 2 wk exposure. Paired boxplot showing the mean peak frequency recorded after the treatments at (A) $29^{\circ} \mathrm{C}$; pH 7.7; (B) $29^{\circ} \mathrm{C}$; pH 7.4; (C) $30^{\circ} \mathrm{C}$; pH 7.7; (D) $30^{\circ} \mathrm{C}$; pH 7.4. The symbol * and ** indicates significant differences ( $p<0.05$ and $p<0.01$ respectively) after 2 wk of exposure. Mean of each treatment is plotted with enlarged black point in the boxplot.

underwater ambient noise emitted by tropical intertidal habitat. The in-vivo experiment exposed the snapping shrimps to increased temperature and decreased $\mathrm{pH}$ over a period of two weeks, which is longer than the daily fluctuation that they are usually exposed to in the wild. The results of this study showed that despite possible morphological or physiological effects as mentioned above, snapping shrimps are able to adapt to temperature and $\mathrm{pH}$ changes without significantly affecting their bioacoustics behaviour. Snapping sounds were still produced but with a change in acoustic characteristics i.e. sound peak frequency. A possible explanation could be the reduction of cavitation bubble strength due to increase in water temperature. Temperature rise increases the saturated vapour pressure of water that weakens the formation and destabilizes the shape of cavitation bubbles. This is evident from the observed frequency characteristics of cavitation implosion sound.

Sounds of different frequencies have different propagation properties underwater. Generally, the propagation of low frequency sound in shallow waters is restricted by water depth . For snapping shrimp noise that originate from shallow water habitats, a reduction in sound frequency could affect propagation distance hence audibility. Considering the importance of snapping shrimp noise as an acoustic cue in the attraction and navigation of marine larvae, loss in acoustic quality may incur ecological implications. Recruitment and settlement to 
habitats in some marine larvae such as crab and fish could be jeopardized due to reduction in the effective range of attraction cues as well as causing a mismatch between signal frequency and hearing sensitivity. It is also likely that due to the miniature size of marine larvae (in comparison to the wavelength of sound wave) they are more sensitive to higher frequency signal. In addition, coral fish larvae, particularly during settlement stage, has been found to prefer the higher frequency component of reef noise.

Long term changes in seawater temperature and $\mathrm{pH}$ can be attributed to global climate change. In previous studies efforts have been made to understand the effects of climate change on marine organisms under laboratory conditions that are comparable to the current study. Here, we report for the first time the potential effect of climate change on the bioacoustics of snapping shrimps. Accordingly, our findings provide an insight into how the natural ambient noise of marine habitats can be affected by climate change, thus providing a new understanding for assessing the overall impact of climate change on the underwater soundscape of marine habitats.

\section{Add-on Information}

Authors' contribution : K.S. Lai: Designed and performed experiments, collected and analysed data; co-wrote the paper; Z.Z. Goh: Performed experiments, collected and analysed data; revised the paper; S.M. Ghazali: Conceived and designed the experiments, analysed data and co-wrote the paper.

Research content : The research content of manuscript is original and has not been published elsewhere.

Ethical approval : Not applicable

Conflict of interest : The authors declare that there is no conflict of interest.

Data from other sources : Not applicable

Consent to publish : All authors agree to publish the paper in Journal of Environmental Biology.

\section{References}

Akamatsu, T., T. Okumura, N. Novarini and H.Y. Yan: Empirical refinements applicable to the recording of fish sounds in small tanks. J. Acoust. Soc. Am., 112, 3073-3082 (2002).

Anestis, A., A. Lazou, H.O. Pörtner and B. Michaelidis: Behavioral, metabolic, and molecular stress responses of marine bivalve Mytilus galloprovincialis during long-term acclimation at increasing ambient temperature. Am. J. Physiol. Regul. Integr. Comp. Physiol., 293, R911-R921(2007).

Au, W.W.L. and K. Banks: The acoustics of the snapping shrimp Synalpheus Parneomeris in Kaneohe Bay. J. Acoust. Soc. Am., 103, 41-47 (1998).

Bohnenstiehl, D.R., A. Lillis and D.B. Eggleston: The curious acoustic behavior of estuarine snapping shrimp: Temporal patterns of snapping shrimp sound in sub-tidal oyster reef habitat. PIOS ONE, 11, e0143691 (2016).

Branch, T.A., B.M. Dejoseph, L.J. Ray and C.A. Wagner: Impacts of ocean acidification on marine seafood. Trends Ecol.Evol., 28, 178$186(2013)$

Caldeira, K. and M.E. Wickett: Ocean model predictions of chemistry changes from carbon dioxide emissions to the atmosphere and ocean. J. Geophys. Res. Oceans, 110, C09S04 (2005).

Cassidy, D.C., G. Holton and F.J. Rutherford: Understanding Physics. $1^{\text {st }}$ Edn., Springer, Switzerland (2002).

Chen, C.T. and F.J. Millero: Speed of sound in seawater at high pressures. J.Acoust. Soc. Am., 62, 1129-1135 (1977).

Dissanayake, A. and A. Ishimatsu: Synergistic effects of elevated $\mathrm{CO}_{2}$ and temperature on the metabolic scope and activity in a shallowwater coastal decapod (Metapenaeus joyneri; Crustacea: Penaeidae). ICES J. Mar. Sci., 68, 1147-1154 (2011).

Everest, F.A., R.W. Young and M.W. Johnson: Acoustical characteristics of noise produced by snapping shrimp. J.Acoust. Soc. Am., 20, 137-142 (1948).

Gazeau, F., C. Quiblier, J.M. Jansen, J.P. Gattuso, J.J. Middelburg and C.H. Heip: Impact of elevated $\mathrm{CO}_{2}$ on shellfish calcification. Geophys. Res. Lett., 34, L07603 (2007).

Højsgaard, S. and U. Halekoh: doBy: Groupwise Statistics, LSmeans, Linear Contrasts, Utilities. R package version 4.6.6. https://CRAN. R-project.org/package=doBy (2020).

Johnson, M.W., F.A. Everest and R.W. Young: The role of snapping shrimp (Crangon and Synalpheus) in the production of underwater noise in the sea. Biol. Bull., 93, 122-138 (1947).

Kim, B.N., J. Hahn, B.K. Choi and B.C. Kim: Snapping shrimp sound measured under laboratory conditions. Jpn. J. Appl. Phys., 49, 07HG04 (2010).

Kim, B.N., J. Hahn, B.K. Choi,B.C. Kim, Y. Park, S.K. Jung and Y.K. Lee: Acoustic characteristics of the snapping shrimp sound observed in the coastal sea of Korea. Jpn. J. Appl. Phys., 50, 07HG04 (2011).

Kirtman, B., S.B. Power, J.A. Adedoyin, G.J. Boer, R. Bojariu, I. Camilloni, F.J. Doblas-Reyes, A.M. Fiore, M. Kimoto, G.A. Meehl, M. Prather, A. Sarr, C. Schär, R. Sutton, G.J. van Oldenborgh, G. Vecchi and H.J. Wang: Near-term Climate Change: Projections and Predictability. In: Climate Change 2013: The Physical Science Basis. Contribution of Working Group I to the Fifth Assessment Report of the Intergovernmental Panel on Climate Change (Eds: Stocker, T.F., D. Qin, G.K. Plattner, M. Tignor, S.K. Allen, J. Boschung, A. Nauels, Y. Xia, V. Bex and P.M. Midgley). Cambridge University Press, Cambridge, United Kingdom and New York, USA (2013).

Knowlton, R.E. and J.M. Moulton: Sound production in the snapping shrimps Alpheus (Crangon) and Synalpheus. Biol. Bull., 125, 311331 (1963).

Kurihara, H., M. Matsui, H. Furukawa, M. Hayashi and A. Ishimatsu: Long-term effects of predicted future seawater $\mathrm{CO}_{2}$ conditions on the survival and growth of the marine shrimp Palaemon pacificus. J. Exp. Mar. Biol. Ecol., 367, 41-46 (2008).

Lesser, M.: Oxidative stress causes coral bleaching during exposure to elevated temperatures. Coral Reefs, 16, 187-192 (1997).

Lillis, A. and T.A. Mooney: Snapping shrimp sound production patterns on Caribbean coral reefs: Relationships with celestial cycles and environmental variables. Coral Reefs, 37, 597-607 (2018).

Mann, R.: The effect of temperature on growth, physiology, and 
gametogenesis in the Manila clam Tapes philippinarum (Adams \& Reeve, 1850). J. Exp. Mar. Biol. Ecol., 38, 121-133 (1979).

Montgomery, J.C., A. Jeffs, S.D. Simpson, M. Meekan and C. Tindle: Sound as an orientation cue for the pelagic larvae of reef fishes and decapod crustaceans. Adv. Mar. Biol., 51, 143-196 (2006).

Montgomery, J.C., N. Tolimieri and O.S. Haine: Active habitat selection by pre-settlement reef fishes. Fish Fish., 2, 261-277 (2001).

Muralisankar, T., P. Kalaivani, S.H. Thangal and P. Santhanam: Growth, biochemical, antioxidants, metabolic enzymes and hemocytes population of the shrimp Litopenaeus vannamei exposed to acidified seawater. Comp.Biochem. Phys. C, 239, 108843 (2020).

Perry, A.L., P.J. Low, J.R. Ellis and J.D. Reynolds: Climate change and distribution shifts in marine fishes. Science, 308, 1912-1915 (2005).

Pörtner, H.O., C. Bock and A. Reipschlager: Modulation of the cost of pH regulation during metabolic depression: A (31) P-NMR study in invertebrate (Sipunculus nudus) isolated muscle. J. Exp. Biol., 203, 2417-2428 (2000)

Pörtner, H.O., M. Langenbuch and B. Michaelidis: Synergistic effects of temperature extremes, hypoxia, and increases in $\mathrm{CO}_{2}$ on marine animals: From earth history to global change. J. Geophys. Res. Oceans, 110, C09S10 (2005).

R Core Team: R:Alanguage and environment for statistical computing. $R$ Foundation for Statistical Computing, Vienna, Austria. URL http://www.R-project.org/ (2018).

Radford, C.A., A.G. Jeffs and J.C. Montgomery: Directional swimming behavior by five species of crab postlarvae in response to reef sound. Bull. Mar. Sci., 80, 369-378 (2007).

Rogers, P.H. and M. Cox: Underwater sounds as a biological stimulus. In: Sensory Biology of Aquatic Animals (Eds.: J. Atema, R.R. Fay, A.N. Popper and W.N. Tavolga). $1^{\text {st }}$ Edn., Springer, New York, USA (1988).

Rossi, T., S.D. Connell and I. Nagelkerken: Silent oceans: Ocean acidification impoverishes natural soundscapes by altering sound production of the world's noisiest marine invertebrate. Proc. Royal Soc. B, 283, 20153046 (2016).

Shima, A., Y. Tomita and T. Ohno: Temperature effects on single bubble collapse and induced impulsive pressure. J. Fluids Eng., 110, 194 199 (1988).

Shirayama, Y. and $\mathrm{H}$. Thornton: Effect of increased atmospheric $\mathrm{CO}_{2}$ on shallow water marine benthos. J.Geophys. Res. Oceans, 110, C09S08 (2005).

Simpson, S.D., M. Meekan, J. Montgomery, R. Mccauley and A. Jeffs: Homeward sound. Science, 308, 221-221 (2005).

Simpson, S.D., M.G. Meekan, A. Jeffs, J.C. Montgomery and R.D. McCauley: Settlement-stage coral reef fish prefer the higherfrequency invertebrate-generated audible component of reef noise. Anim. Behav., 75, 1861-1868 (2008).

Simpson, S.D., M.G. Meekan, R.D. McCauley and A. Jeffs: Attraction of settlement-stage coral reef fishes to reef noise. Mar. Ecol. Prog. Ser., 276, 263-268 (2004).

Sokolova, I.M.: Cadmium effects on mitochondrial function are enhanced by elevated temperatures in a marine poikilotherm, Crassostrea virginica Gmelin (Bivalvia: Ostreidae). J. Exp. Biol., 207, 26392648 (2004).

Stanley, J.A., C.A. Radford and A.G. Jeffs: Induction of settlement in crab megalopae by ambient underwater reef sound. Behav. Ecol., 21, $113-120(2010)$.

Tolimieri, N., A. Jeffs and J.C. Montgomery: Ambient sound as a cue for navigation by the pelagic larvae of reef fishes.Mar. Ecol. Prog. Ser., 207, 219-224 (2000).

Urick, R.J.: Principles of Underwater Sound. McGraw-Hill, New York, USA(1983).

Verma, D. and V. Tomar: Structural-nanomechanical property correlation of shallow water shrimp, Pandalus platyceros exoskeleton at elevated temperature. J. Bionic Eng., 11, 360-370 (2014).

Versluis, M., B. Schmitz, A. Von Der Heydt and D. Lohse: How snapping shrimp snap: Through cavitating bubbles. Science, 289, 2114$2117(2000)$

Wickham, H.: ggplot2: Elegant Graphics for Data Analysis. SpringerVerlag New York. ISBN 978-3-319-24277-4, https://ggplot2. tidyverse.org (2016).

Wickins, J.F.: The effect of reduced pH on carapace calcium, strontium and magnesium levels in rapidly growing prawns (Penaeus monodon fabricius). Aquaculture, 41, 49-60 (1984). 